\title{
Prospective assessment of the value of a chest radiograph in the performance of diagnostic cardiac catheterisation in adults
}

\author{
R H Stables, B Trotman-Dickenson
}

\begin{abstract}
Objective-To assess the value of a chest radiograph in the performance of diagnostic cardiac catheterisation in adults. Patients and methods-340 consecutive diagnostic cardiac catheter procedures in adults at one institution. It is normal practice for primary operators to report the results of catheterisation using a graphical user interface database system. Data entry screens were modified to present a study questionnaire to assess the use made of the chest radiograph in the performance of the catheter procedure. Setting-Tertiary referral cardiac centre. Results-The chest radiograph was judged of value in only 12/340 procedures (4\%). The radiograph influenced catheter selection in six procedures, the volume of injected radiographic contrast medium in five, and showed an abnormality important to the planning or conduct of the procedure in six procedures. A dual benefit was reported in five procedures. Utility of the radiograph was related to the pre-catheter diagnosis. It proved of value in only $2 / 283(0.7 \%)$ procedures with a working diagnosis of ischaemic heart disease, influencing only catheter selection. Its utility was greater in congenital heart disease, contributing in $3 / 4$ (75\%) procedures, dilated cardiomyopathy in $2 / 6(33 \%)$ procedures, and valvar heart disease in $4 / 35(11.5 \%)$ procedures. Conclusions-In the performance of diagnostic cardiac catheterisation in adults access to a recent chest radiograph contributes little to the conduct of investigations performed for suspected ischaemic heart disease, but may be of greater value in congenital disease, valve abnormalities, and dilated cardiomyopathy.
\end{abstract}

(Br Heart f 1994;72:540-541)

Diagnostic cardiac catheterisation is increasingly performed as a day case procedure. Many patients are referred after evaluation at other hospitals, and although a chest radiograph may have been performed, the film is often not available at the time of catheterisation. Some cardiac centres insist on the availability of a recent chest radiograph before proceeding to diagnostic cardiac catheterisation. ${ }^{1}$ The aim of this study was to assess the value of the chest radiograph in the performance of adult diagnostic cardiac catheterisation.

\section{Patients and methods}

At the Royal Brompton Hospital diagnostic catheter reports are completed by the primary operator using a locally designed graphical user interface computer database system. Specialised data entry screens guide the operator through a structured reporting process with data entry by mouse click action on graphics and automated drop down menus. ${ }^{2}$ Data are entered in the catheterisation laboratory on completion of a patient examination. An audit of 1000 consecutive procedures found the data record to be greater than $96 \%$ complete.

We amended the data entry screens to prospectively assess the value of a chest radiograph in the performance of a case. The primary operator was presented with the question

"Did you derive any information from the pre-catheter chest radiograph that was of value in the performance of the catheter procedure?"

The operator was forced to make a "yes" or "no" response to this question before further data entry was allowed. Those answering "yes" were then presented with an additional, previously hidden, questions to identify the way or ways in which the radiograph had been of value. Operators could describe benefit by the selection of one or more of these options: $(a)$ in the choice of catheter; $(b)$ in deciding volumes of radiographic contrast agent to be used; $(c)$ in the identification a radiological abnormality important in the planning or conduct of the procedure; and $(d)$ other.

Over a two month period 19 operators recorded 340 consecutive diagnostic procedures in adults. No significant procedure related complications were recorded for these patients. Over $75 \%$ of procedures were performed by six operators in the registrar and senior registrar grade.

The patients were typical for a population undergoing diagnostic catheterisation in the United Kingdom except that congenital heart disease in adults (four patients) may be over represented, reflecting a specialised aspect of the practice of our institution. Table 1 shows the pre-catheter diagnostic groups. The patient cohort comprised 339 subjects, one patient undergoing two procedures. A total of $252(74 \%)$ patients were men and the mean (SD) age was 60 (11) years (range 83-21).
The Royal Brompton Hospital, London 27 June 1994 
Table 1 Diagnostic groups of the patients studied

\begin{tabular}{lc}
$\begin{array}{l}\text { Pre-catheter } \\
\text { diagnostic group }\end{array}$ & $\begin{array}{l}\text { No }(\%) \\
\text { of patients } \\
(n=340)\end{array}$ \\
\hline $\begin{array}{l}\text { Ischaemic heart } \\
\text { disease }\end{array}$ & $283(83)$ \\
$\begin{array}{l}\text { Valvar heart } \\
\text { disease }\end{array}$ & $35(10)$ \\
$\begin{array}{l}\text { Cardiomyopathy } \\
\text { dilated }\end{array}$ & $6(2)$ \\
$\begin{array}{l}\text { Adult congenital } \\
\text { Pre-heart-lung } \\
\text { transplantation }\end{array}$ & $4(1)$ \\
assessment & $4(1)$ \\
$\begin{array}{l}\text { Cardiomyopathy } \\
\text { Research }\end{array}$ & $3(<1)$ \\
$\begin{array}{l}\text { Pulmonary or } \\
\text { pulmonary }\end{array}$ & $2(<1)$ \\
vascular & $340(100)$ \\
\hline \begin{tabular}{l} 
Total \\
\hline
\end{tabular} &
\end{tabular}

\section{Results}

A positive response to the primary question was made in only 12 cases, representing $4 \%$ of the total. These responses were made by eight different operators with no one operator declaring use of the chest radiograph on more than two occasions. Table 2 gives a breakdown of these cases by pre-catheter diagnosis and details of the type of information provided by the chest radiograph. In patients in whom a significant abnormality was identified the radiograph was reviewed by a radiologist (BTD). In all instances its nature was found to be a previously recognised abnormality in the size or contour of the cardiac silhouette or great vessels.

\section{Discussion}

The aim of this study was to assess the value of a chest radiograph in the performance of diagnostic cardiac catheterisation in adults. We did not attempt to examine its role in the evaluation of cardiac patients or its value as a screening test in this population.

We believe that most chest radiographs obtained as an aid to cardiac catheterisation are unnecessary and that their avoidance would reduce costs and limit the patients' exposure to ionising radiation. It has been estimated that the lifetime risk for the induction of a fatal cancer from chest radiography is between $0 \cdot 7-2 \cdot 0 / 10^{6}$ patient examinations. ${ }^{3}$

Grier et al evaluated the use of the preprocedure chest radiograph in peripheral and coronary angiography. ${ }^{1}$ They considered its contribution to case management, concluding that it was unnecessary in the absence of specific clinical indications that would justify the examination in its own right. They commented that the impact of the chest radiograph on the performance of the procedure was difficult to assess as relevant findings may have been evident on fluoroscopy, during

Table 2 Cases in which the chest radiograph was judged to be of value, sorted by diagnostic group. The number of instances where each type of benefit was described is identified in the four rightmost columns

\begin{tabular}{|c|c|c|c|c|c|}
\hline $\begin{array}{l}\text { Pre-catheter } \\
\text { diagnostic } \\
\text { group } \\
\text { (No of cases) }\end{array}$ & $\begin{array}{l}\text { No of cases when } \\
\text { chest radiograph } \\
\text { of value } \\
\text { (\% of total) }\end{array}$ & $\begin{array}{l}\text { Benefit: } \\
\text { catheter } \\
\text { selection }\end{array}$ & $\begin{array}{l}\text { Benefit: } \\
\text { contrast } \\
\text { volume }\end{array}$ & $\begin{array}{l}\text { Benefit: } \\
\text { radiographic } \\
\text { abnormality }\end{array}$ & $\begin{array}{l}\text { Benefit: } \\
\text { other }\end{array}$ \\
\hline Adult congenital heart disease (4) & $3(75)$ & 1 & 2 & 2 & - \\
\hline Cardiomyopathy dilated (6) & $2(33)$ & 1 & 1 & - & - \\
\hline Valvar heart disease (35) & $4(11)$ & 1 & 2 & 3 & - \\
\hline Pre-heart-lung transplantation (4) & $1(25)$ & 1 & - & 1 & - \\
\hline Ischaemic heart disease (283) & $2(0 \cdot 7)$ & 2 & - & - & - \\
\hline Total & $12(4)$ & 6 & 5 & 6 & - \\
\hline
\end{tabular}

angiography, or identified previously. ${ }^{1}$ Our study focused on these procedural aspects to identify instances where the radiograph had been of definite value to the angiographer in the conduct of the investigation.

A recent chest radiograph may have additional value if a patient was to proceed directly after catheterisation to a surgical procedure involving a general anaesthetic. The Royal College of Radiologists has evaluated the role of preoperative chest radiography and found that it was indicated in certain well defined circumstances, including patients with established cardiorespiratory disease. ${ }^{4}$ The risk, however, of an emergency operation resulting from a complication of diagnostic catheterisation was found to be only $0.08 \%$ in a recent United Kingdom survey.5 An emergency operation is more common after interventional procedures, occurring in between 2 and $7 \%$ of patients. ${ }^{67} \mathrm{~A}$ recent chest radiograph may therefore have greater potential value in diagnosis when subsequent angioplasty is considered.

\section{Conclusions}

The value of a recent chest radiograph in the performance of diagnostic cardiac catheterisation in adults is limited and its potential application can be predicted from the pre-catheter diagnosis. It appears to be of greatest value in cases of congenital heart disease, dilated cardiomyopathy, and valvar heart disease in adults and probably should be available for the performance of these procedures. In contrast, it rarely contributes when the underlying diagnosis is ischaemic heart disease and these patients should not be subjected to examination as an aid to catheterisation.

1 Grier DJ, Watson LJ, Hartnell GC, Wilde P. Are routine chest radiographs prior to angiography of any value? Clin Radiol 1993;48:131-3.

2 Stables RH, Chronos NA, Buller NP. A graphical user interface database for the results of cardiac catheterisation [abstract]. 7 Am Coll Cardiol 1994;335A

3 Anonymous. Report by the Royal College of Radiologists and the National Radiological Protection Board. Patient dose reduction in diagnostic radiology. Documents of the National Radiological Protection Board. 1990;1(3):9-13.

4 Royal College of Radiologists. Pre-operative chest radiography. Lancet 1979;ii:82-6.

5 de Bono D. Complications of diagnostic cardiac catheterisation: results from 34041 patients in the United Kingdom confidential enquiry into cardiac catheter complications. Br Heart f 1993;70:297-300.

6 Cowley MJ, Dorros G, Kelsey SF, Van Raden M, Detre KM. Acute coronary events associated with percutaneous transluminal coronary angioplasty. $A m \mathcal{f}$ Cardiol 1984;53:12C-6C.

7 BCIS. Cardiac interventional procedures in the United Kingdom during 1991. Br Heart $\mathcal{f}$ 1993;70:201-3. 